\title{
Correlates of Anxiety Disorder among Patients with Seizure Disorders in a Neuropsychiatric Hospital in Nigeria
}

\author{
Nasiru Olamide Madandola ${ }^{1}$, Shehu Sale ${ }^{1}$, Adebayo Sunday Adebisi1 ${ }^{*}$, Ayodele Obembe ${ }^{2}$, \\ Abdulfatai Tomori Bakare ${ }^{2}$, Ishak Abioda Danjuma ${ }^{1}$ \\ ${ }^{1}$ Department of Psychiatry, Federal Neuropsychiatric Hospital, Kware, Sokoto, Nigeria \\ ${ }^{2}$ Department of Psychiatry, Usmanu Danfodio University Teaching Hospital, Sokoto, Nigeria \\ Email: *docotufodunrin@yahoo.com
}

How to cite this paper: Madandola, N.O., Sale, S., Adebisi, A.S., Obembe, A., Bakare, A.T. and Danjuma, I.A. (2019) Correlates of Anxiety Disorder among Patients with Seizure Disorders in a Neuropsychiatric Hospital in Nigeria. Open Journal of Psychiatry, 9, 68-80.

https://doi.org/10.4236/ojpsych.2019.92006

Received: January 8, 2019

Accepted: March 1, 2019

Published: March 4, 2019

Copyright $\odot 2019$ by author(s) and Scientific Research Publishing Inc. This work is licensed under the Creative Commons Attribution International License (CC BY 4.0).

http://creativecommons.org/licenses/by/4.0/

\section{Open Access}

\begin{abstract}
Background: Anxiety may complicate epilepsy as is often the case out of the various psychiatric comorbidities patients can suffer from when they are suffering from epilepsy. The aim of this study was to estimate the prevalence of anxiety among patients that had epilepsy and also to examine the associated socio-demographic and clinical factors that are associated with and eventually predictive of this psychiatric comorbidity. Materials and Method: This study was a descriptive cross-sectional study that involved the use of General Health Questionnaire, version 28 (GHQ-28) and the Composite International Diagnostic Interview (CIDI), which were used independently to investigate each of the 400 consecutive participants in this study over a period of 24 weeks. The diagnosis of epilepsy was based on the International Classification of Diseases (ICD10) diagnostic criteria and all participants with anxiety were diagnosed using CIDI. A proforma Questionnaire was used to assess the socio-demographic and some clinical variables among patients. Logistic regression was done to determine the predictors of anxiety in the study participants. Results: When screened with GHQ-28, 71 people (17.8\%) met criteria for caseness. When all the participants were examined using CIDI, 12 (3\%) were diagnosed with generalized anxiety disorder. The variables found to be the predictors of anxiety were family history of psychiatric disorders $(\mathrm{p}=$ $0.045)$, fear of having seizure $(\mathrm{p}=0.036)$ and GHQ caseness $(\mathrm{p}=0.002)$. Conclusion: The study showed the existence of anxiety disorders among patients with seizure disorder. This is an important association with seizure disorders which is often overlooked. It will be beneficial to these patients if this co-morbidity is actively looked out for. Patients suffering from seizure disorder that have a family history of mental illness should be considered for an assessment of anxiety disorder. Psychological intervention for anticipatory fear of seizure should be employed by mental health professionals.
\end{abstract}




\section{Keywords}

Epilepsy, Anxiety, Correlates, Nigeria

\section{Introduction}

Epileptic seizures as an entity can be traced back to about 2000 B.C. in the ancient region of Mesopotamia. The word "epilepsy" was coined from Latin and Greek words and it means "seizure" or "to seize upon". It is believed to be brought about by the god of the moon and that is why anyone afflicted is termed a lunatic. Ancient Indian Ayurveda describes different kinds of diseases that resemble epilepsy with a special reference to one that results in a momentary loss of memory [1]. One of the biblical mentions of epilepsy was in the book of Mark 9:17-22, where the value of spiritual healing in treating epilepsy was emphasized [2]. Epilepsy occurs in all mammalian species, and seems to be more frequent with increased complexity of mammalian brains [3]. It is one of the most common and serious neuropsychiatric disorders in the world [4] [5]. It is also the most common non-infectious neuropsychiatric disease in developing African countries like Nigeria [4]. Also, it affects at least 50 million people in the world and about 100 million people will have at least one epileptic seizure at some time in their lives. Epilepsy affects all ages with about 10 million people being directly affected in Africa. It is responsible for an enormous amount of suffering. Epilepsy in African rural and urban communities is often attributable to supernatural causes such as witchcraft and it is often treated by traditional healers [6]. Persons with epilepsy are disadvantaged as they are often shunned and discriminated against in education, employment and in marriage. This is due to the fact that epilepsy is seen as a highly contagious and shameful disease in Africa [7]. Some studies have shown that about $50 \%$ of patients with epilepsy develop psychiatric disorders, with the most common being depression, anxiety and psychotic disturbances. The psychiatric symptomatology is often classified according to how they relate in time (temporality) to seizure occurrence; they are thus classed as ictal, pre-ictal/prodromal, post-ictal or inter-ictal [8].

Comorbidity is a condition in clinical practice where several diseases coexist within the same patient at the same time [9]. Psychiatric comorbidities in epilepsy seem to be a common occurrence and among them anxiety disorders are highly frequent and have a profound influence on the quality of life of epilepsy patients [10]. Anxiety as a psychiatric disorder affects about 18 percent of the population and lasts at least six months. It must be treated promptly else it can get worse [11]. Anxiety is an experience of fear or apprehension in response to anticipated internal or external danger, accompanied by some or all of the following signs: muscle tension, restlessness, sympathetic hyperactivity, and cognitive signs and symptoms like: confusion, alertness, decreased concentration, or fear of losing control. Anxiety in patients with epilepsy can be ictal, postictal, or 
interictal [12]. Though stress and anxiety do not cause seizure they may be a trigger [13]. Fitch has shown that the rate of anxiety in epilepsy ranges from 10 to $32 \%$ in people already living with epilepsy [14]. It could be quite difficult separating the anxiety that is as a result of a chronic disease from pathologic anxiety as studies investigating anxiety in epilepsy have been relatively few compared to depression in epilepsy [12]. There have been challenges in treatment as some of the medications used in treating anxiety disorder in epilepsy cause lowering of seizure threshold or they inadvertently interfere with metabolism of antiepileptics [15]. Anxiety disorders are very frequently under diagnosed which result in delay in intervention. Many at times such patient are not treated at all thus leaving a wide treatment gap [16]. Anxiety disorder is expected to be on the increase in coming years as performance expectation from patients with epilepsy is likely to increase the anxiety and apprehension in these patients [9]. A 2006 case control study was done by Fatoye et al. about interictal anxiety and depressive symptoms among 52 patients with epilepsy as compared to 52 healthy control groups. The Hospital Anxiety and Depression Scale (HADS) were used to screen participants. The result shows significant association between polytherapy and anxiety and illness longer than 10 years and depression [17]. Adewuya and Bola also did a study on 102 patients on the prevalence and the risk factors of anxiety and depressive disorders among adolescents with epilepsy. They got a prevalence of $31.37 \%$ for all types of anxiety disorders and $28.43 \%$ for depressive disorder. This study deviated from their study in that they did their study among adolescents while this was done among adults. They also used Diagnostic Interview Schedule for Children (DISC-IV) to assess for anxiety while this study used both GHQ and CIDI to assess for anxiety.

The psychosocial variables associated with Anxiety in epilepsy are: The stress of being labeled as having seizure disorder which has a lot of impact on the development of anxiety. Studies have also found similar association with depression and the development of psychotic symptoms in epileptics [18]. Also, performance expectation put a lot of patients suffering from seizure disorder under anxious states [9]. Polytherapy is a major clinical variable that is associated with anxiety in patients with seizure disorder [17]. Other generalized factors will be female gender and age of more than 40 years [19].

\section{Objective}

To determine socio-demographic and clinical factors that are associated with the occurrence of anxiety among patients with seizure disorders at Federal Neuropsychiatric Hospital, Kware Sokoto.

\section{Methodology}

The study was carried out at the outpatient department of the Federal Neuropsychiatric Hospital, Kware Sokoto, Nigeria. The sample size of 400 was derived using the sample size estimate for proportion [20] [21]. In an earlier study con- 
ducted by Longe and Osuntokun in 1989, the prevalence of epilepsy in the general population was 6/1000, while Gureje in 1991 reported a prevalence of $37.3 \%$. Using the sample size estimate for proportion:

$$
n=Z^{2} p q / d^{2}
$$

where $n=$ desired sample size,

$Z=1.96$ (95\% confidence interval),

$p=$ Estimated prevalence of the variable,

$q=1-p$,

$d=$ degree of accuracy at 0.05 .

To allow for attrition, $10 \%$ of the calculated sample size is added. This gives a sample size of 394. Thus an approximated sample size of 400 was used in this study.

The Clinical (bedside) diagnosis that was used to define epilepsy was the International Classification of Diseases (ICD-10) codes for Epilepsy and Seizures. While the Anxiety module of the Composite International Diagnostic Interview (CIDI) was used to define Anxiety disorder.

Adults diagnosed with seizure disorder for at least 6months prior to participation, that utilize the healthcare facility and that accepted to participate in the study were recruited consecutively. The exclusion criteria were: 1) Participants that are below 18 years or above 60 years, 2) Non epileptic patients, 3) Patients that declined to participate or withdrew consent at any point, 4) Patients with status epilepticus, active psychotic symptoms which could not allow probable interview or other life threatening conditions. Approval for the research was obtained from the Research and Ethical committee of the Federal Neuropsychiatric Hospital, Kware, Sokoto.

Participants were interviewed using a semi-structured socio-demographic questionnaire designed by the researchers using relevant literatures. The questionnaire detailed the socio-demographic variables of the respondents like age, gender, marital status, ethnicity, employment status, place of residence, educational status, and religion. This was the introductory aspect of the questionnaire.

The Psychological and Clinical variables documented were the duration of illness, frequency of seizure, age at illness onset, previous substance use disorder, presence of recurrent/uncontrolled seizure, any current use of antiepileptic(s), presence of previous hospital admission, recurrent presence of fear of having seizure, level of social support, change in lifestyle and family history of mental illness. The socio-demographic questionnaire and the English or Hausa version of the General Health Questionnaire (GHQ) questionnaire (A self-administered validated screening instrument that was developed in the 1970s aimed at detecting psychiatric disorders in the general population) was then administered on all the participants. All patients were further assessed using the Anxiety module of Composite International Diagnostic Interview-CIDI \{A fully structured validated instrument developed in 1990 for the assessment of psychiatric disorders according to the diagnostic criteria of International Classification of Diseases 
(ICD) and Diagnostic and Statistical Manual of Mental Disorders (DSM)\}.

\subsection{Study Design}

It was a cross-sectional descriptive study.

\subsection{Data Analysis}

Data collected was collated and entered into the computer using the Statistical Package for Social Sciences (SPSS) version 20. Scattered numerical data like age of participants in year, age at seizure onset and the duration of seizure disorder in months were recoded into groups with specific group intervals. The numerical (continuous) data were subjected to means and standard deviations (S.D) and the means were compared using t-test. For categorical variables, descriptive statistics included frequency distributions and cross tabulations in each category. The proportions were compared using chi-square $\left(\chi^{2}\right)$ test. All the variables were examined for their relationship to the overall clinical psychopathologies of anxiety. The data was represented in tables to differentiate the demographic, psychological and clinical data for generalized anxiety disorder. All tests of significance was set at $\mathrm{p}<0.050$. Variables that were statistically significant were further subjected to logistic regression analysis to determine the predictors of the Generalized Anxiety disorder in seizure disorder.

Study Period was from September, 2017 to March, 2018.

\section{Results}

\subsection{Sociodemographic Characteristics of Participants That Had Anxiety}

Among the 400 participants, $12(3.0 \%)$ had Anxiety. Among which 8 (3.0\%) were males and $4(3.0 \%)$ were females. A large proportion of the subjects, 153 (96.2\%) in the Unemployed/Social class $\mathrm{V}$ group had no anxiety, while the remaining 6 (3.8\%) were having anxiety. The majority of the subjects, 174 (43.5\%) were married, out of which $168(96.6 \%)$ had no anxiety disorders leaving only 6 (3.4\%) with the disorder. Only 150 (37.5\%) subjects had western education out of which $3(2.0 \%)$ were suffering from anxiety disorder. This is shown in Table 1.

\subsection{Psychological Characteristics of Participants That Had Generalized Anxiety Disorder}

Table 2 showed psychological variables when cross-tabulated between those with anxiety disorder and those without. Among the 12 patients with anxiety disorder, 9 (75.0\%) always have the fear of having seizure as compared to 3 $(25.0 \%)$ who did not have the fear $\left(\chi^{2}=19.554, p=0.000\right)$. There were also significant differences between those with anxiety disorders and those without as it related to change in their lifestyles; $9(75.0 \%)$ vs. $3(25.0 \%)\left(\chi^{2}=4.188, p=0.041\right)$ and family history of mental illnesses; $7(58.3 \%)$ vs. $5(41.7 \%)\left(\chi^{2}=9.517, \mathrm{p}=\right.$ $0.006)$. 
Table 1. Comparison of the sociodemographic characteristics in participants that had anxiety and those without anxiety $(\mathrm{N}=400)$.

\begin{tabular}{|c|c|c|c|c|c|}
\hline Variable & $\begin{array}{l}\text { No anxiety group } \\
(\text { No./\% })(\mathrm{N}=388)\end{array}$ & $\begin{array}{c}\text { Anxiety group } \\
(\text { No./\% })(\mathrm{N}=12)\end{array}$ & $\mathrm{X}^{2} / \mathrm{t}$ & D.F & $\mathbf{P}$ \\
\hline \multicolumn{6}{|l|}{ Age group in years } \\
\hline $18-40$ & $349(97.7 \%)$ & $8(2.3 \%)$ & \multirow{3}{*}{$\mathrm{T}=-1.592$} & \multirow{3}{*}{11.267} & \multirow{3}{*}{70.139} \\
\hline $41-60$ & $41(91.1 \%)$ & $4(8.9 \%)$ & & & \\
\hline Mean (S.D) & $28.74(9.06)$ & $35.50(13.12)$ & & & \\
\hline \multicolumn{6}{|l|}{ Gender } \\
\hline Male & $258(97.0)$ & $8(3.0)$ & $\mathrm{X}^{2}=0.00$ & 1 & 0.630 \\
\hline Female & $130(97.0)$ & $4(3.0)$ & & & \\
\hline \multicolumn{6}{|l|}{ Occupation by Social Class } \\
\hline Unemployed/Social classV & $153(96.2)$ & $6(3.8)$ & $\mathrm{X}^{2}=0.543$ & 1 & 0.553 \\
\hline Others & $235(97.5)$ & $6(2.5)$ & & & \\
\hline \multicolumn{6}{|l|}{ Marital Status } \\
\hline Married & $168(96.6)$ & $6(3.4)$ & $\mathrm{X}^{2}=0.213$ & 1 & 0.645 \\
\hline Others & $220(97.3)$ & $6(2.7)$ & & & \\
\hline \multicolumn{6}{|l|}{ Educational Status } \\
\hline Western Education & $147(98.0)$ & $3(2.0)$ & $\mathrm{X}^{2}=0.825$ & 1 & 0.547 \\
\hline Nil/Islamic & $241(96.4)$ & $9(3.6)$ & & & \\
\hline \multicolumn{6}{|l|}{ Ethnicity } \\
\hline Hausa & $341(96.6)$ & $12(3.4)$ & $\mathrm{X}^{2}=1.647$ & 1 & 0.218 \\
\hline Others & $47(100.0)$ & $0(0.0)$ & & & \\
\hline \multicolumn{6}{|l|}{ Religion } \\
\hline Islam & $382(97.0)$ & $12(3.0)$ & $\mathrm{X}^{2}=0.188$ & 1 & 0.664 \\
\hline Christianity & $6(100.0)$ & $0(0.0)$ & & & \\
\hline
\end{tabular}

Table 2. Comparison of the psychological characteristics of the study participants in the anxiety and non-anxiety group $(\mathrm{N}=400)$.

\begin{tabular}{cccccc}
\hline Variables & $\begin{array}{c}\text { No anxiety group } \\
(\text { No./\%) }(\mathbf{N}=388)\end{array}$ & $\begin{array}{c}\text { Anxiety group } \\
(\text { No./\%) }(\mathbf{N}=12)\end{array}$ & $\mathbf{X}^{2}$ & D.F & P \\
\hline Fear of having seizure & & & & & \\
No & $307(97.1)$ & $3(25.0)$ & 19.554 & 1 & $<0.001$ \\
Yes & $81(20.9)$ & $9(75.0)$ & & & \\
Seizure worry & & & & & \\
No & $215(55.4)$ & $5(41.7)$ & 0.889 & 1 & 0.258 \\
Yes & $173(44.6)$ & $7(58.3)$ & & & \\
Change in lifestyle & & & & & \\
No & $213(54.9)$ & $3(25.0)$ & 4.188 & 1 & 0.041 \\
Yes & $175(45.1)$ & $9(75.0)$ & & & \\
Social support & & & & & \\
Reduced & $46(11.9)$ & $2(16.7)$ & 0.562 & 2 & 0.755 \\
No change & $174(44.8)$ & $6(50.0)$ & & & \\
Increased & $168(43.3)$ & $4(33.3)$ & & & \\
Family history of mental illness & & & & & \\
No & $307(79.1)$ & $5(41.7)$ & 9.517 & 1 & 0.006 \\
Yes & $81(20.9)$ & $7(58.3)$ & & & \\
\hline
\end{tabular}




\subsection{Clinical Characteristics of Participants with Generalized Anxiety Disorder}

Table 3 illustrated that those subjects with physical complications were more likely to be have anxiety disorder $7(8.5 \%)$ compared to those without $5(1.6 \%)$ $\left(\chi^{2}=10.865, \mathrm{p}=0.004\right)$. Patients that had a short duration $(<100$ days $)$ of last seizure occurrence were more likely to be having anxiety disorders $12(4.2 \%)$ when compared to those without anxiety disorder $0(0 \%)(\mathrm{T}=12.689, \mathrm{p}=$ 0.000). Also those that had a previous history of hospitalization due to seizure disorder were more likely to have anxiety 4 (8.9\%) when compared to those without $8(2.3 \%)\left(\chi^{2}=6.043, \mathrm{p}=0.035\right)$.

\subsection{Multivariate Logistic Regressions for Predictors of Anxiety}

Shown in Table 4, all variables that were significant on chi square were recruited to determine the predictors of anxiety among seizure patients.

The following variables were thus used for anxiety disorder: Seizure fear, Change in lifestyle, family history of psychiatric illness, duration since last seizure, physical complications, previous hospitalization and GHQ caseness. Only fear of having seizure $(p=0.036)$, family history of mental illnesses $(p=0.045)$ and GHQ caseness $(p=0.002)$ were significant predictors of anxiety.

\section{Discussion}

Psychiatry morbidity is an important accompaniment of seizure disorder to the extent that some researchers anticipated the inclusion of such comorbidities in seizure diagnostic criteria [22]. The focus of this study was the correlates of anxiety disorder in people already having seizure disorder which is a common comorbidity with seizure disorder [23] [24]. In this study, not only the prevalence but the predictors of anxiety in seizure patients were examined.

Twelve participants (3\%) of the study population had generalized anxiety. This is similar to the finding of Christian Brandt et al. (2010) where they found a diagnosis of generalized anxiety disorder among patient suffering from epilepsy of $3.1 \%$ [25]. It was also similar to the result gotten by Tunde-Ayinmode et al. when the result was converted to percentage within the study population of 63 respondents [19]. A similar study in Bauchi got an anxiety prevalence of $4.1 \%$ [26]. However, this rate is lower than many studies with reported rate of between 9\% - 39\% [16] [18] [27]. These differences in rates may be due to the different socio-cultural situations of the study populations as the quoted studies were all done outside Sokoto State and also most of the studies used different instruments for the assessment of the participants. More also, this study population was stabilized on drugs for six months prior to data collection. This might have helped them to be able to institute better coping mechanisms to combat some of the anxiety they may have had.

When patients were presented with the question asking them about the psychological state of having a fear that is directed to the seizure that they are having, 
Table 3. Comparison of the clinical characteristics of the study participants in the anxiety and non-anxiety group $(\mathrm{N}=400)$.

\begin{tabular}{|c|c|c|c|c|c|}
\hline Variables & $\begin{array}{c}\text { Noanxiety group } \\
(\text { No./\%) } \\
(\mathrm{N}=388)\end{array}$ & $\begin{array}{c}\text { Anxiety group } \\
(\text { No./\%) } \\
(\mathrm{N}=12)\end{array}$ & $\mathrm{X}^{2} / \mathrm{t}$ & D.F & $\mathbf{P}$ \\
\hline \multicolumn{6}{|l|}{ Seizure Diagnosis } \\
\hline Grand Mal & $294(97.4)$ & $8(2.6)$ & $X^{2}=0.522$ & 1 & 0.335 \\
\hline Others & $94(95.9)$ & $4(4.1)$ & & & \\
\hline \multicolumn{6}{|c|}{ Age at seizure onset (yrs) } \\
\hline $0-9$ & $92(95.8 \%)$ & $4(4.2 \%)$ & & & \\
\hline $10-19$ & $163(98.2 \%)$ & $3(1.8 \%)$ & & & \\
\hline $20-29$ & $90(96.8 \%)$ & $3(3.2 \%)$ & & & \\
\hline $30-39$ & $35(100.0 \%)$ & $0(0.0 \%)$ & $\mathrm{T}=-0.632$ & 11.233 & 0.540 \\
\hline $40-49$ & $5(83.3 \%)$ & $1(16.7 \%)$ & & & \\
\hline$\geq 50$ & $3(75.0 \%)$ & $1(25.0 \%)$ & & & \\
\hline \multicolumn{6}{|l|}{ Range: $>1$ - 59} \\
\hline Mean (S.D) & $16.3153(10.25)$ & $18.5417(17.59)$ & & & \\
\hline \multicolumn{6}{|c|}{ Duration of seizure (months) } \\
\hline $0-99$ & $155(97.5 \%)$ & $4(2.5 \%)$ & & & \\
\hline $100-199$ & $125(97.7 \%)$ & $3(2.3 \%)$ & & & \\
\hline $200-299$ & $77(97.5 \%)$ & $2(2.5 \%)$ & & & \\
\hline $300-399$ & $23(92.0 \%)$ & $2(8.0 \%)$ & $\mathrm{T}=-1.026$ & 11.299 & 0.326 \\
\hline $400-499$ & $5(83.3 \%)$ & $1(16.7 \%)$ & & & \\
\hline$\geq 500$ & $3(100.0 \%)$ & $0(0.0 \%)$ & & & \\
\hline \multicolumn{6}{|l|}{ Range: 6 - 510} \\
\hline Mean (S.D) & $145.36(100.06)$ & $190.50(157.36)$ & & & \\
\hline \multicolumn{6}{|c|}{ Duration since last Seizure (Days) } \\
\hline $0-100$ & $274(95.8)$ & $12(4.2)$ & & & \\
\hline$\geq 101$ & $144(100)$ & $0(0.0)$ & $\mathrm{T}=12.689$ & 387 & $<0.001$ \\
\hline \multicolumn{6}{|l|}{ Range: 1 - 5475} \\
\hline Mean (S.D) & $215.58(558.70)$ & $19.67(31.31)$ & & & \\
\hline \multicolumn{6}{|c|}{ Physical complications } \\
\hline No & $313(98.4)$ & $5(1.6)$ & $\mathrm{X}^{2}=10.865$ & 1 & 0.004 \\
\hline Yes & $75(91.5)$ & $7(8.5)$ & & & \\
\hline \multicolumn{6}{|c|}{ Seizure in the last one month } \\
\hline No & $192(98.5)$ & $3(1.5)$ & $X^{2}=2.793$ & 1 & 0.083 \\
\hline Yes & $196(95.6)$ & $9(4.4)$ & & & \\
\hline \multicolumn{6}{|c|}{ Hard drug prior seizure } \\
\hline No & $345(97.0)$ & $11(3.0)$ & $\mathrm{X}^{2}=0.003$ & 1 & 0.717 \\
\hline Yes & $34(97.1)$ & $1(2.9)$ & & & \\
\hline \multicolumn{6}{|c|}{ Current hard drug use } \\
\hline No & $360(97.0)$ & $11(3.0)$ & $\mathrm{X}^{2}=0.022$ & 1 & 0.600 \\
\hline Yes & $28(96.6)$ & $1(3.4)$ & & & \\
\hline \multicolumn{6}{|l|}{ Seizure Drug } \\
\hline Monodrug & $350(97.0)$ & $11(3.0)$ & $\mathrm{X}^{2}=0.28$ & 1 & 1.000 \\
\hline Multiple Drugs & $38(97.4)$ & $1(2.6)$ & & & \\
\hline \multicolumn{6}{|l|}{ Medical disorder } \\
\hline No & $351(97.5)$ & $9(2.5)$ & $\mathrm{X}^{2}=3.093$ & 1 & 0.108 \\
\hline Yes & $37(92.5)$ & $3(7.5)$ & & & \\
\hline \multicolumn{6}{|c|}{ Previous Hospitalization } \\
\hline No & $347(97.7)$ & $8(2.3)$ & $X^{2}=6.043$ & 1 & 0.035 \\
\hline Yes & $41(91.1)$ & $4(8.9)$ & & & \\
\hline
\end{tabular}




\section{Continued}

\begin{tabular}{|c|c|c|c|c|c|}
\hline \multicolumn{6}{|c|}{ Maternal Pregnancy complications } \\
\hline No & $276(96.8)$ & $9(3.2)$ & \multirow{3}{*}{$\mathrm{X}^{2}=0.233$} & \multirow{3}{*}{2} & \multirow{3}{*}{0.890} \\
\hline Yes & $6(100.0)$ & $0(0.0)$ & & & \\
\hline Not reported & $106(97.2)$ & $3(2.8)$ & & & \\
\hline \multicolumn{6}{|c|}{ Delivery related complications } \\
\hline No & $273(96.8)$ & $9(3.2)$ & \multirow{3}{*}{$\mathrm{X}^{2}=0.337$} & \multirow{3}{*}{2} & \multirow{3}{*}{0.845} \\
\hline Yes & $9(100.0)$ & $0(0.0)$ & & & \\
\hline Not reported & $106(97.2)$ & $3(2.8)$ & & & \\
\hline \multicolumn{6}{|l|}{ GHQ Caseness } \\
\hline No & $327(99.4)$ & $2(0.6)$ & \multirow[t]{2}{*}{$\mathrm{X}^{2}=36.447$} & \multirow[t]{2}{*}{1} & \multirow[t]{2}{*}{$<0.001$} \\
\hline Yes & $61(85.9)$ & $10(14.1)$ & & & \\
\hline \multicolumn{6}{|l|}{ EEG Report } \\
\hline Negative & $157(97.5)$ & $6(2.5)$ & \multirow[t]{2}{*}{$X^{2}=0.438$} & \multirow[t]{2}{*}{1} & \multirow[t]{2}{*}{0.353} \\
\hline Positive & $231(96.3)$ & $6(3.7)$ & & & \\
\hline
\end{tabular}

Table 4. Logistic regression analysis for the predictors of generalized anxiety disorder in the participants.

\begin{tabular}{cccccc}
\hline Predictor Variable & B & P Value & $\operatorname{Exp(B)}$ & $\begin{array}{c}\text { Exp(B) (95\% CI) } \\
\text { Lower }\end{array}$ & upper \\
\hline Fear of Having Seizure & -1.559 & $\underline{0.036}$ & 0.210 & 0.049 & 0.901 \\
Life style Change & 0.462 & 0.589 & 1.587 & 0.297 & 8.482 \\
Family History of MI & -1.395 & $\underline{0.045}$ & 0.248 & 0.064 & 0.967 \\
Duration since last seizure & 0.023 & 0.153 & 1.024 & 0.991 & 1.057 \\
Seizure Complication & 1.390 & 0.056 & 4.013 & 0.965 & 16.680 \\
Previous Hospitalization & -1.124 & 0.153 & 0.325 & 0.069 & 1.520 \\
GHQ Caseness & -2.710 & $\underline{0.002}$ & 0.067 & 0.012 & 0.364 \\
Constant & -0.260 & 0.754 & 0.771 & & \\
\hline
\end{tabular}

MI = Mental Illness.

more patients that came with the diagnosis of anxiety disorder had higher reported feelings of seizure fear when compared to those without anxiety ( $\mathrm{p}=$ 0.036). This shows that the feeling of fear of having seizure may not just be narrowly for seizure but a broader hidden anxiety disorder. About two-third (75.0\%) of patients that had anxiety had recurrent fear of having seizure; this only shows an association between those that proclaim their fear of having seizure and the broader generalized anxiety disorders. Due to the scope of this study, it is rather difficult to delineate if anxiety disorder triggers seizure or that seizure is the cause of anxiety disorder but what it shows is that having seizure fear is a predictor of having anxiety disorder. It is understandably so that the fear of having seizure is akin to anxiety and it is no surprise that people that professed their fear had more anxiety disorder when compared to those without. The mere thought of being embarrassed by a sudden manifestation that is out of one's control can elicit an anticipatory feeling in people suffering from epilepsy, making them to always be on the edge [10]. An example where seizure was a 
trigger for anxiety disorder was the WHO report by Kenjiro Fukao where it was noted that fear of having seizure can metamorphosize to generalized anxiety disorder through amygdala dysfunction. This may result in anxiety symptoms due to persistent firing of the amygdala and the surrounding regions [28]. The amygdale performs a primary role in the processing of memory, decision-making and emotional responses like fear, and aggressive behaviours. The amygdala is considered part of the limbic system and it is at very close proximity to the temporal lobe; so it has the features of both limbic and temporal lobe epilepsy. The limbic system is the locus of emotion and since anxiety is a form of emotion, abnormal firing of the limbic system can present as anxiety. Steimer (2002) also reported that the locus coeruleus may be the locus of abnormal neuronal firing in some epilepsy. Since this is the nucleus for adrenaline, discharge from the locus coeruleus can present with features similar to anxiety disorder due to excessive sympathetic discharge. Furthermore, neurons in this area may project to the paraventricular nucleus in the hypothalamus thus leading to the activation of the Hypothalamus-Pituitary-Adrenal (HPA) axis. The triggering of this axis gives an anxiety response by the massive release of sympathetic neurotransmitters [29].

Another major predictor of anxiety disorder was family history of psychiatric illness $(p=0.045)$. When patients were asked about the history of psychiatric illness among their family members, those that answered "yes" were more likely to be diagnosed with anxiety disorder when compared to those that said "no". Adewuya and Ola (2005) included "parents psychopathology" which is a narrower form of family history of mental illness as one of the significant variables in people with anxiety disorder in their study [30]. This is in keeping with most studies in psychiatry in particular and in medicine in general where a family history of a disorder is a pointer to the heritability of such disorder. The closely linked the proband is with an affected relative the more the risk of having anxiety disorder [10] [31]. A research done by McGregor (2014) suggested the following novel susceptibility genes among which were: MMP9, EGR2, EGR4, NTF4, and ARC, as candidates for anxiety pathogenicity [32]. Patients that carried defective aforementioned genes were more susceptible to anxiety disorders. The suggestion that discernable genes were involved in the pathogenesis of anxiety disorder in seizure lays claim to the likelihood of anxiety disorder being genetic as suggested by the presence of family history of psychiatric illness.

\section{Conclusion}

This study found the prevalence of anxiety in seizure disorder patients to be $3 \%$. This is relatively low compared to some studies but high and even in consonance with others. The low findings may be due to the fact that each of the participants was diagnosed and had been on medication(s) at least six months prior to this study. Family history of mental illness and fear of having seizure are the predictors of having generalized anxiety disorders in people living with epilepsy. Ef- 
forts targeted at managing epilepsy should also be channeled at asking appropriate questions about associated anxiety disorder with focus on adequate and timely management.

\section{Limitations}

The study was a cross-sectional one and thus may not be sensitive to changes in the levels of the measurements over time.

It is a hospital based study and may not represent entirely what obtains in the community.

Lastly, a brain Computed Tomography scan or Magnetic Resonance Imaging in addition to the Electroencephalogram should have been one of the parameters for assessing the participants but this was not possible due to inability of patients to afford the cost the brain imaging investigations.

\section{Conflicts of Interest}

The authors declare no conflicts of interest regarding the publication of this paper.

\section{Disclosure}

The authors have nothing to disclose.

\section{Funding}

No external funding was sought for this research work.

\section{Statement of Authorship}

AO, NOM, conceived the study; NOM, ASA, SS, designed the study protocol; NOM, SS, collected the data; NOM, AO, IAD, drafted the manuscript; SS, ASA, TOB revised the manuscript.

\section{References}

[1] Magiorkinis, E., Sidiropoulou, K. and Diamantis, A. (2011) Hallmarks in the History of Epilepsy: From Antiquity till the Twentieth Century. In: Foyaca-Sibat, H., Ed., Novel Aspects on Epilepsy [Internet], InTech, Athens, Greece, 131-158.

http://www.intechopen.com https://doi.org/10.5772/19010

[2] Smith, S. (2016) What Does the Bible Say about Epilepsy? https://www.openbible.info/topics/epilepsy

[3] Reynolds, E.H., Bharucha, N.E. and Sander, J.W. (2005) Epilepsy: The Disorder. WHO, Geneva, 15-28.

[4] Olubunmi, A.O., Ogunrin, A., Sc, O.B. and Olubunmi, A.O. (2006) Epilepsy in Nigeria-A Review of Etiology, Epidemiology and Management. Benin Journal of Postgraduate Medicine, 8, 25.

https://pdfs.semanticscholar.org/88cb/2c582069b509feff76afac37ba225298d5ef.pdf

[5] Damtie, Z.G., Grunitzky, E.K., Kalangu, K.K.N., Madzokere, C., Matuja, W., Mielke, 
J., Pahl, K. and Rwenhamo, P. (2004) Epilepsy in the WHO African Region: Bridging the Gap. WHO, Geneva, 56 p.

[6] Peltzer, K. (2001) Perceptions of Epilepsy among Black Students at a University in South Africa. Curationis, 24, 62-67. https://doi.org/10.4102/curationis.v24i2.833

[7] Kabir, M., Iliyasu, Z., Abubakar, I.S., Kabir, Z.S. and Farinyaro, A.U. (2005) Knowledge, Attitude and Beliefs about Epilepsy among Adults in a Northern Nigerian Urban Community. Annals of African Medicine, 4, 107-112.

[8] Foong, J. (2015) Psychiatric Disorders in Epilepsy. London, 4 p. https://www.epilepsysociety.org.uk

[9] Titlic, M., Basic, S., Hajnsek, S. and Lusic, I. (2009) Comorbidity Psychiatric Disorders in Epilepsy: A Review of Literature. Bratislava Medical Journal, 110, 105-109.

[10] Ekinci, O. (2011) Anxiety Disorders in Epilepsy. In: Szirmai, A., Ed., Anxiety and Related Disorders [Internet], InTech, Hatay, Turkey, 217-228.

http://www.intechopen.com https://doi.org/10.5772/21158

[11] Falcone, T. and Timmons-Mitchell, J. (2013) Pediatric Epilepsy and Anxiety [Internet]. https://my.clevelandclinic.org/

[12] Sukumar, S. (2014) Factors Influencing Anxiety among Epilepsy Patients at Selected Hospital in Chennai. International Journal of Engineering Research and General Science [Internet], 2, 479-486.

[13] Novakova, B., Harris, P.R., Ponnusamy, A. and Reuber, M. (2013) The Role of Stress as a Trigger for Epileptic Seizures. Epilepsia, 54, 1866-1676. https://doi.org/10.1111/epi.12377

[14] Epilepsy, F.T. Depression, Anxiety and Services Available to Adults Living with Epilepsy [Internet]. https://my.clavelandclinic.org

[15] Kar, S.K., Tekkalaki, B., Mohapatra, S. and Saha, R. (2015) Mental Health Perspectives of Epilepsy: Focus on Anxiety Disorders. Delhi Psychiatry Journal, 18, 7-15.

[16] Phabphal, K., Sattawatcharawanich, S., Sathirapunya, P. and Limapichart, K. (2007) Anxiety and Depression in Thai Epileptic Patients. Japan Medical Association, 90, 2010-2015. http://www.medassocthai.org/journal

[17] Fatoye, F., Mosaku, K.S., Komolafe, M. and Adewuya, A.O. (2006) Interictal Anxiety and Depression Symptoms in Nigerians with Epilepsy: A Controlled Study. Epilepsy \& Behavior, 9, 312-316. http://www.ncbi.nlm.nih.gov/pubmed/16861046

[18] Stefanello, S., Marín-léon, L., Fernandes, P.T., Li, L.M. and Botega, N.J. (2011) Depression and Anxiety in a Community Sample with Epilepsy in Brazil. Arquivos de Neuro-Psiquiatria, 69, 342-348. https://doi.org/10.1590/S0004-282X2011000300015

[19] Tunde-Ayinmode, M.F., Abiodun, O.A., Ajiboye, P.O., Buhari, O.I.N. and Sanya, E.O. (2014) Prevalence and Clinical Implications of Psychopathology in Adults with Epilepsy Seen in an Outpatient Clinic in Nigeria. General Hospital Psychiatry, 36, 703-708. http://www.ncbi.nlm.nih.gov/pubmed/25264339

[20] Israel, G.D. (1992) Determining Sample Size. University of Florida, Gainesville. http://www.tarleton.edu/academicassessment/documents/Samplesize.pdf

[21] Kish, L. (1995) Survey Sampling. Wiley, Hoboken, 643 p.

[22] Kanner, A.M. (2016) Psychiatric Comorbidities in Epilepsy: Should They Be Considered in the Classification of Epileptic Disorders? Epilepsy and Behavior, 64, 306-308. http://linkinghub.elsevier.com/retrieve/pii/S1525505016302219

[23] Bragatti, J.A., Torres, C.M., Isolan, G.R. and Bianchin, M.M. (2011) Psychiatric 
Comorbidities of Epilepsy: A Review. Journal of Neurology and Neurophysiology, 2, 1-10. https://www.omicsonline.org

[24] Gureje, O. (1991) Interictal Psychopathology in Epilepsy. Prevalence and Pattern in a Nigerian Clinic. The British Journal of Psychiatry, 158, 700-705.

http://www.ncbi.nlm.nih.gov/pubmed/1907212

[25] Brandt, C., Schoendienst, M., Trentowska, M., May, T.W., Pohlmann-Eden, B., Tuschen-Caffier, B., et al. (2010) Prevalence of Anxiety Disorders in Patients with Refractory Focal Epilepsy-A Prospective Clinic Based Survey. Epilepsy \& Behavior, 17, 259-263. https://doi.org/10.1016/j.yebeh.2009.12.009

[26] Ayanda, K.A. and Sulyman, D. (2016) The Predictors of Psychiatric Disorders among People Living with Epilepsy as Seen in a Nigerian Tertiary Health Institution. Nigerian Medical Journal, 57, 24-30. http://www.nigeriamedj.com/text.asp?2016/57/1/24/180559

[27] LaFrance, W.C., Kanner, A.M. and Hermann, B. (2008) Psychiatric Comorbidities in Epilepsy. International Review of Neurobiology, 83, 347-383.

[28] Fukao, K. (2012) Psychic Seizures and Their Relevance to Psychosis in Temporal Lobe Epilepsy. In: Stevanovic, D., Ed., Epilepsy-Histological, Electroencephalographic and Psychological Aspects, InTech, Kyoto, 199-216.

http://www.intechopen.com https://doi.org/10.5772/18777

[29] Steimer, T. (2002) The Biology of Fear- and Anxiety-Related Behaviors. Dialogues in Clinical Neuroscience, 4, 231-249.

http://www.ncbi.nlm.nih.gov/pubmed/22033741

[30] Adewuya, A.O. and Ola, B.A. (2005) Prevalence of and Risk Factors for Anxiety and Depressive Disorders in Nigerian Adolescents with Epilepsy. Epilepsy \& Behavior, 6, 342-347. http://www.ncbi.nlm.nih.gov/pubmed/15820341

[31] Gaitatzis, A., Carroll, K., Majeed, A. and Sander, J.W. (2004) The Epidemiology of the Comorbidity of Epilepsy in the General Population. Epilepsia, 45, 1613-1622.

[32] Mcgregor, N.W. (2014) The Identification Novel Susceptibility Genes in Anxiety Disorders. Stellenbosch University, Stellenbosch. https://www.researchgate.net/publication/26547624 